\title{
Conflicts at Work - The Relationship with Workplace Factors, Work Characteristics and Self-rated Health
}

\author{
Gabriel OXENSTIERNA ${ }^{1 *}$, Linda L. MAGNUSSON HANSON ${ }^{1}$, Maria WIDMARK ${ }^{1}$, \\ Kristina FINNHOLM${ }^{1}$, Cecilia STENFORS ${ }^{1}$, Stig ELOFSSON ${ }^{2}$ and Töres THEORELL ${ }^{1}$ \\ ${ }^{1}$ Stress Research Institute, Stockholm University, SE-106 91 Stockholm, Sweden \\ ${ }^{2}$ Department of Social Work, Stockholm University, SE-106 91 Stockholm, Sweden \\ Received January 13, 2009 and accepted February 8, 2011 \\ Published online in J-STAGE June 21, 2011
}

\begin{abstract}
Few studies have considered the work environment in relation to workplace conflicts and those who have been published have included relatively few psychosocial work environment factors. Little research has been published on the consequences of workplace conflicts in terms of employee health. In this study, the statistical relationships between work and workplace characteristics on one hand and conflicts on the other hand are examined. In addition, the relationship between conflicts at work and self-rated health are described. The study population was derived from the Swedish Longitudinal Occupational Survey of Health (SLOSH) 2006; $n=5,141$. Among employees at workplaces with more than 20 employees $(n=3,341), 1,126(33.7 \%)$ responded that they had been involved in some type of conflict during the two years preceding the survey. Among the work and workplace characteristics studied, the following factors were independently associated with increased likelihood of ongoing conflicts: Conflicting demands, emotional demands, risk of transfer or dismissal, poor promotion prospects, high level of employee influence and good freedom of expression. Factors that decreased the likelihood of ongoing conflicts were: Good resources, good relations with management, good confidence in management, good procedural justice (fairness of decisions) and good social support. After adjustment for socioeconomic conditions the odds ratio for low self-rated health associated with ongoing conflict at work was $2.09(1.60-2.74)$. The results provide a good starting point for intervention and prevention work.
\end{abstract}

Key words: Conflicts, Work, Work environment, Workplace factors, Work characteristics, Self-rated health

\section{Introduction}

Workplace conflict is common and widespread. In a study conducted in the 1990's by the Finnish Central Bureau of Statistics, over 50 percent of those interviewed reported that they had experienced conflicts with colleagues and over 60 percent that they had experienced conflict with superiors ${ }^{1)}$. In Sweden, roughly one-third of persons in the labour force report that they

*To whom correspondence should be addressed.

E-mail: Gabriel.oxenstierna@stressforskning.su.se have been involved in conflicts with superiors in the 12 months prior to the survey, while just as large a share report that they have been involved in conflicts with workmates (Work Environment Statistics 2007, The Swedish Work Environment Authority/Statistics Sweden). This study also shows that workplace conflicts are as common among women as among men.

Conflicts are often categorized either as factual or interpersonal. Rahim ${ }^{2}$ separates conflicts into four sub-categories: intrapersonal (within one and the same individual), interpersonal (in relationships with others), within a (work) group, and between (work) 
groups. Conflicts arising from organisational or societal structures are termed system or structural conflicts. Interpersonal conflicts at work are generally associated with three components; disagreement, interference and negative emotion ${ }^{3)}$, and may have greater or lesser effect on the state of health of those involved. However, conflicts seldom have only negative consequences ${ }^{4}$.

Conflict is a natural part of any organisation's development, where lesser conflicts tend to pass without leaving negative traces. Conflicts should therefore not be seen as incidental happenings but rather as part of a dynamic process ${ }^{5)}$. The consequences may also differ depending on the outcome of the conflict.

The predominant explanation for workplace conflicts has tended to be psychological factors, i.e., individual behaviour. But although psychological factors have dominated for a long time in conflict research, there are also results that point to organisational structure and other conditions within the organisation that may generate conflict. A reasonable assumption is that both psychological and organisational factors can explain the emergence of conflicts at the workplace.

\section{The importance of workplace conditions for conflicts}

Many workplaces today are characterised by more or less constant instability. Restructuring has become a natural and regular feature in the planning of most business activities ${ }^{6}$. Reorganisations and downsizings are often coupled with conflicts and leadership issues. Leymann ${ }^{7)}$ gives the following examples of organisational triggers of conflict situations: poor leadership, poor work supervision, unwillingness of superiors to intervene in friction/ill-feeling between workmates, and large numbers of employees of different backgrounds and ethnicity. In a meta-analysis by Spector $\& \mathrm{Jex}^{8}$, role conflict was strongly correlated to interpersonal conflicts as well as to role ambiguity and negative affectivity, the two latter factors less strongly, however. Appelberg et al. ${ }^{9)}$ studied the relationship between organisational and individual factors and the emergence of interpersonal conflicts among 14,578 respondents (aged 24-64). Both organisational and individual factors turned out to contribute to the emergence of workplace conflicts, where the organisational factors included monotonous, fastpaced work and white collar jobs. A recent study by De Raeve et al..$^{10)}$ based on longitudinal data $(\mathrm{n}=9,241)$ also showed that workplace factors play a major role in the emergence of interpersonal conflicts both between workmates and between workers and their superiors. One year after follow up, it was observed that risk factors were role ambiguity, poor physical environment and overtime.

Workplace factors that appeared to have had a pre- ventive effect against conflicts both between workmates and between workers and their superiors were social support and career opportunities. Other studies have suggested that openness of communication, feelings of connection and a common identity are important factors for the prevention of interpersonal conflicts ${ }^{11-13)}$.

\section{The connection between interpersonal conflict and health}

The previous studies showed that a high degree of interpersonal conflict or workplace conflicts was associated with negative feelings, counter-productive manner, work incapacity among women, stress symptoms, increased risk for mental ill health and low self-reported health ${ }^{14-22)}$.

Previous studies showed also that conflict with superiors was associated with long-term sick leave, mental ill health, physical ill-health, risk for emotional exhaustion, depressive symptoms ${ }^{23-26)}$. In a study by Hagerty \& Williams ${ }^{27)}$ conflicts had a strong negative effect on employees' feeling of connection to the workplace and were an important contributory factor to employee depressions.

As noted above, much of the research on workplace conflicts has found an explanation in psychological factors - the personality and behaviour of the individual -while far less research has aimed at clarifying the role of the workplace environment as engenderer of conflict where only a relatively few psychosocial work environment factors have been included and there is clearly a need for more research on the consequences of workplace conflicts on employee health.

\section{Aims and issues}

The intention of this study was to investigate whether and how work and workplace characteristics generate conflict and in that case, how such conflicts affect health. The study is explorative. Organisational factors were scrutinized to see which might be coupled to conflict and the effects of such conflicts on employee health. In a second step a longitudinal approach will be taken, when the second wave of the Swedish Longitudinal Occupational Survey of Health (SLOSH) is available (see below). The problem of bullying in working life was excluded in this study although it certainly constitutes an aspect of workplace conflict. Our intention is to address that problem in a separate paper.

Specific questions:

1. What were the sources of conflict? How important was the conflict? What was the result?

2. What work and workplace characteristics are associated with conflicts at work?

3. How are conflicts at work related to employees' self-rated health? 


\section{Material and Methods}

\section{The study population}

The study population was derived from $\mathrm{SLOSH}^{28,}$ 29), based on the respondents from the 2003 Swedish Work Environment Survey (SWES). SWES is conducted biennially by Statistics Sweden (SCB) on a sample drawn from the Labour Force Survey (LFS). The SWES sample is a nationally representative sample of people aged 16-64 in the active labour force covering all occupational groups. In connection with the LFS telephone interviews, respondents were asked to fill out a supplementary self-completion questionnaire about the physical and psychosocial work environment, workrelated morbidity, education and training, and attitudes to work. In March 2006, 9,154 of the respondents to SWES were followed up by means of two extended self-completion questionnaires, one addressed to those in gainful employment at least $30 \%$ of full time and one to those out of the labour force. A total of 5,985 individuals (65\% of the eligible SWES participants) responded to the follow up, of which 5,141 used the questionnaire for persons in employment and 844 for people out of the labour force.

In the present study only those who answered the questionnaire for persons in employment were used. Some characteristics of the working population have been presented previously ${ }^{29)}$. SLOSH contains information about the number of persons employed at each respondent's workplace. Many companies are familyowned or small businesses where there is often hardly any organisational structure to speak of. In this context social support is mostly synonymous with family solidarity. We have therefore chosen only to include respondents in workplaces with 20 employees or more $(\mathrm{n}=3,394)$. In addition, 50 persons had not responded to the question about conflicts. Thus, the final number of subjects in the study was 3,344. The study has been approved by the Regional Research Ethics Board in Stockholm.

\section{Measures}

Conflict was used both as an independent and as a dependent variable in the study. The question was formulated in the following way: In the past two years, have you been drawn into any kind of conflict at your workplace? Response alternatives were yes or no.

To those who answered in the affirmative the question then was "What was the source of the conflict/ conflicts?" Response alternatives were chosen from the open responses given by respondents in the pilot survey as follows: job conditions; resources and staffing; work demands and work pace; work tasks/duties; authorisa- tions and responsibility; leadership and your immediate superior; colleagues; patients/customers/clients/passengers/pupils; other, where several alternatives could be chosen.

The next question asked was: In general, how important was the conflict? (Responses: Completely unimportant; Quite unimportant; Quite important; Very important). Third: From your point of view, what was the result of the conflict/these conflicts? (Very good; Quite good; Quite poor; Very poor); and fourth: Is the conflict still going on? (Yes; No).

Most of these dimensions, variables and variable groups were first identified in a pilot study ${ }^{30}$ ) and then to a large extent incorporated in SLOSH. The work characteristics included the dimensions Demands; Authority to make decisions, and Resources. Demands were divided into quantitative, conflicting, emotional, social, intellectual, and physical. In discussions regarding operationalisation of exposure variables we felt a need to differentiate between such "work" factors that are close to the individual on one hand ("work and individual") and the dimensions on the "workplace" level on the other hand. The latter category included: Goals; Structure; Management; Freedom; Democracy and justice; and Humanity and social support. From the dimension "conflicts and conflict management", conflict was used as outcome. A detailed description of the variables is available in the appendix (Appendix, Conflicts at work: www.stressforskning.su.se).

In the pilot survey ${ }^{30}$ ) we were able to show that the Demands and Humanity \& social support factors were directly correlated with the two outcome factors Health and Symptoms of stress, after adjustment for all other factors. All other associations were indirect. Since our intention was to investigate the relationships between work and workplace factors and conflict and health we maintained the theoretical division between "work and individual" and "workplace" factors including all variables and variable groups in those main divisions and added conflict and (self-rated) health as outcomes. Leadership, social support and conflicting demands (role conflict and role ambiguity) were factors shown to be important in previous studies $\left.{ }^{7}, 8,10\right)$. Details of questions and measurement properties can be found in the Appendix. These dimensions and sub-dimensions were used as predictors of workplace conflict.

In order to give the reader an idea of the magnitude of the work conflict-health association in this particular context, we included one simple generally accepted health outcome, self rated health. A large number of studies have shown that self-rated health is a strong independent predictor of both future morbidity and mortality ${ }^{31)}$. General health was measured with the ques- 
tion: How would you rate your general state of health? (Very poor; Quite poor; Neither good nor bad; Quite good; Very good). Those who rated their general health as neither good nor bad or poor were considered to have poor general health. Additional measures derived from the questionnaire included supervisory duties (Yes; No), principal employer (private company, local government district, local government county/region, central government, other), education (compulsory school, 2-yr upper secondary school/vocational training, 3- or 4-yr upper secondary school, university or the equivalent $(<3 \mathrm{yr})$, university or the equivalent $(3 \mathrm{yr}+)$ ), marital status (single, married/cohabiting), financial situation, relationships with friends (Very poor; Poor; Noncommittal; Good; Very good), smoking (Yes daily, Yes sometimes, No), alcohol consumption (Never; Once a month or less; 2-4 times a month; 2-3 times a week or more), body mass index, and general life satisfaction. General life satisfaction was assessed by the question: All things considered, how satisfied or dissatisfied are you with your life as a whole? (Very dissatisfied; Moderately dissatisfied; A little dissatisfied; No feelings either way; A little more satisfied than dissatisfied; Moderately satisfied; Very satisfied). We further considered age (10-yr periods) and birth country (Sweden, other) by means of register data.

\section{Data analyses}

When used as the dependent variable, only ongoing conflicts were considered and contrasted with no conflicts. When used as the independent variable, all conflicts were used. In addition, we formed three categories; no conflict(s), terminated conflict(s), and ongoing conflict(s). Moreover, we used terminated conflict(s) with poor result compared with no conflict(s) as the independent variable. $\chi^{2}$ tests were used to examine whether conflicts differed by sex and status. In order to create meaningful dimensions of workplace and work characteristics, factor analyses were performed and internal consistencies were calculated for some of the sub-dimensions of interest. Associations between workplace and work characteristics and conflicts, as well as between conflicts and self-rated health were estimated with multiple logistic regression analysis. The results of the logistic regression analyses were presented as standardized odds ratios (ORs) with 95\% confidence intervals indicating the change in likelihood of conflict (Tables 3 and 4) and poor health (Table 5) associated with an increase of one standard deviation on the explanatory factor's scale. All work characteristics were entered into the same model for mutual adjustment. A similar model was fitted including all workplace characteristics. When studying the influence of work and workplace characteristics on conflicts, the results were adjusted for potential confounding from age, marital status, birth country, education, and principal employer. Separate models were first fitted for men and women as well as for supervisory duties. The final analyses were, however, combined as no significant interactions were detected in regression analyses by means of including regression terms in the logistic regression models. Sex and supervisory duties were therefore included among the other covariates. When studying the relationship between conflicts and poor general health, financial situation and relationships with friends were also considered. In subsidiary models we further considered lifestyle factors (smoking, alcohol consumption, body mass index) and general life satisfaction. Finally, correlations between work characteristics and workplace characteristics and sources of conflicts were examined, and significant correlations with correlation coefficients between $0.15-0.20$ are presented.

Due to missing values on separate variables not all observations could be used in the multivariate analyses. The analyses of workplace characteristics had the most excessive internal loss of observations. A separate analysis shows that missing values are dispersed among most of the variables, indicating no systematic pattern. An explanation of this could be that the questionnaire was quite long, making it easy for the respondent to overlook some question(s). A problem that arises when the researcher is using a large number of independent variables is the risk of multicollinearity. Analysis of this show that tolerance levels were above or at the lower limit usually accepted. All data analyses were carried out in SPSS 16.0.

\section{Results}

\section{Descriptive statistics on conflicts}

Among employees at workplaces with more than 20 employees, 1,126 (33.7\%) responded that they had been involved in some type of conflict in the past two years (500 (31.8\%) among men and $626(34.4 \%)$ among women). This was more common among people with supervisory duties $(n=441(42.6 \%))$ compared with other employees $(\mathrm{n}=672(28.9 \%))$. Among men with supervisory duties $40 \%$, and among women with supervisory duties $47.5 \%$, had been involved in conflicts of some kind. Among other employees the corresponding numbers were $27.8 \%$ among men and $30.4 \%$ among women.

For those who had been involved in conflict(s), the importance of the conflict(s) and whether the conflict(s) were still ongoing at the time of the survey in 2006 is presented in Table 1. Men, especially those with supervisory duties, reported important conflicts to a signifi- 
Table 1. Response distribution concerning significance and duration of conflict(s) for those who in 2006 (out of 3,341 participants in workplaces with more than 20 employees) stated that they had been involved in any type of conflict in the past two years

\begin{tabular}{|c|c|c|c|c|c|c|c|c|c|c|}
\hline & & \multicolumn{3}{|c|}{ All } & \multicolumn{3}{|c|}{ Supervisors } & \multicolumn{3}{|c|}{ Other employees } \\
\hline & & All & Men & Women & All & Men & Women & All & Men & Women \\
\hline & $\mathrm{n}=$ & 1,126 & 500 & 626 & 441 & 223 & 218 & 672 & 273 & 399 \\
\hline & & $\%$ & $\%$ & $\%$ & $\%$ & $\%$ & $\%$ & $\%$ & $\%$ & $\%$ \\
\hline \multirow[t]{2}{*}{ Importance } & Unimportant & 67 & 64 & 72 & 68 & 62 & 75 & 68 & 65 & 70 \\
\hline & Important & 33 & 36 & 28 & 32 & 38 & 25 & 32 & 35 & 30 \\
\hline \multirow[t]{2}{*}{ Duration } & Terminated & 61 & 61 & 61 & 60 & 58 & 61 & 61 & 63 & 60 \\
\hline & Still ongoing & 39 & 39 & 39 & 40 & 42 & 39 & 39 & 37 & 40 \\
\hline
\end{tabular}

Percentage (\%).

Table 2. Response distribution with reference to the source of the conflicts for those who in 2006 had been involved in conflicts in the past two years

\begin{tabular}{|c|c|c|c|c|c|c|c|c|c|}
\hline & \multicolumn{3}{|c|}{ All } & \multicolumn{3}{|c|}{ Supervisors } & \multicolumn{3}{|c|}{ Other employees } \\
\hline & All & Men & Women & All & Men & Women & All & Men & Women \\
\hline Source $^{1}$ & 1,126 & 500 & 626 & 441 & 223 & 218 & 672 & 273 & 399 \\
\hline & $\%$ & $\%$ & $\%$ & $\%$ & $\%$ & $\%$ & $\%$ & $\%$ & $\%$ \\
\hline Colleagues & 36 & 32 & 40 & 36 & 36 & 37 & 37 & 29 & 42 \\
\hline Work tasks/duties & 34 & 37 & 30 & 35 & 39 & 31 & 33 & 36 & 31 \\
\hline Resources and staffing & 32 & 38 & 28 & 40 & 45 & 35 & 27 & 32 & 24 \\
\hline $\begin{array}{l}\text { Job conditions, e.g. pay or working } \\
\text { hours }\end{array}$ & 29 & 38 & 22 & 29 & 37 & 21 & 29 & 38 & 22 \\
\hline $\begin{array}{l}\text { Leadership quality and relation to } \\
\text { immediate superior }\end{array}$ & 27 & 29 & 25 & 26 & 25 & 28 & 28 & 32 & 25 \\
\hline Work demands and pace & 24 & 27 & 22 & 29 & 32 & 26 & 21 & 24 & 19 \\
\hline Authorisations and responsibility & 20 & 21 & 18 & 25 & 26 & 24 & 16 & 17 & 16 \\
\hline $\begin{array}{l}\text { Patients, customers, clients, } \\
\text { passengers, pupils }\end{array}$ & 16 & 14 & 17 & 20 & 20 & 21 & 12 & 8 & 14 \\
\hline Other & 8 & 8 & 8 & 9 & 9 & 9 & 7 & 8 & 7 \\
\hline
\end{tabular}

${ }^{1}$ Several concomitant response alternatives were allowed.

Percentage (\%).

cantly higher degree than women.

In Table 2, the sources of the conflict(s) according to the respondents are presented. Job conditions, resources and staffing, and work tasks/duties were the most frequent sources of conflicts for men, whereas for women it was conflicts with colleagues. Furthermore, people with supervisory duties were significantly more often than others in conflict about resources and staffing, work demands and work pace, authorisations and responsibility, as well as about patients, customers, clients, passengers, or pupils.

Concerning the result of the conflict(s), a significantly higher proportion of employees with non-supervisory duties reported poor results. The result of conflicts that were terminated prior to the 2006 survey was reported as poor by $14.7 \%$ of the men and $15.8 \%$ of the women with supervisory duties and by $25.4 \%$ of the men and $19.4 \%$ of the women with non-supervisory duties.
We observe that patients, customers, clients, pupils, and passengers, i.e. persons not belonging to the organisation, were the most uncommon source of workplace conflicts $(15.9 \%)$.

\section{Relationship with workplace and work characteristics}

Table 3 presents odds ratios and 95\% confidence intervals from the multiple regressions assessing the relationships between work characteristics and ongoing conflicts $(n=2,482)$. A higher degree of conflicting demands, emotional demands and lack of resources as well as risk of transfer or dismissal was relatively strongly associated with ongoing conflicts. A weak relationship was also noted for poor promotion prospects in the adjusted model. Further adjustment for principal employer did not notably affect the estimates (data not shown). The corresponding analysis regarding workplace characteristics is presented in Table 4 
Table 3. Associations between work characteristics and ongoing conflicts $(n=2,482)$. Multiple logistic regression. Standardized odds ratios with $95 \%$ confidence limits

\begin{tabular}{lllll}
\hline Dimensions & & Mean $(\mathrm{Min} / \mathrm{Max}) / \%$ & $\mathrm{OR}^{1}$ & $95 \% \mathrm{CI}^{1}$ \\
\hline Demands & Quantitative demands & $2.95(1 / 4)$ & 1.03 & $0.83-1.28$ \\
& Conflicting demands & $2.58(1 / 4)$ & $\mathbf{1 . 6 2}$ & $\mathbf{1 . 3 6}-\mathbf{1 . 9 4}$ \\
& Emotional demands & $2.68(1 / 4)$ & $\mathbf{1 . 5 7}$ & $\mathbf{1 . 3 0 - 1 . 9 0}$ \\
& Social demands & $3.41(1 / 4)$ & 0.87 & $0.71-1.07$ \\
& Intellectual demands & $85.9 \%$ & 1.02 & $0.68-1.52$ \\
& Physical demands & $2.07(1 / 6)$ & 1.00 & $0.91-1.09$ \\
Decision authority & Decision authority & $3.04(1 / 4)$ & 0.93 & $0.79-1.10$ \\
Resources & Resources & $82.0 \%$ & $\mathbf{0 . 4 9}$ & $\mathbf{0 . 3 8}-\mathbf{0 . 6 4}$ \\
Security of employment & Risk of transfer or dismissal & $28.8 \%$ & $\mathbf{1 . 5 6}$ & $\mathbf{1 . 2 2}-\mathbf{2 . 0 0}$ \\
Career opportunities & Poor promotion prospects & $2.49(1 / 5)$ & $\mathbf{1 . 1 5}$ & $\mathbf{1 . 0 5}-\mathbf{1 . 2 7}$ \\
\hline
\end{tabular}

${ }^{1}$ Adjusted for age, sex, education, and supervisory duties.

Table 4. Associations between workplace characteristics and ongoing conflicts $(\mathrm{n}=\mathbf{2 , 0 8 6})$. Multiple logistic regression. Standardized odds ratios with $95 \%$ confidence limits

\begin{tabular}{|c|c|c|c|c|}
\hline Dimensions & & Mean $(\operatorname{Min} / \operatorname{Max}) / \%$ & $\mathrm{OR}^{1}$ & $95 \% \mathrm{CI}^{1}$ \\
\hline \multirow[t]{2}{*}{ Goals } & Guided by organisational goals & $3.98(1 / 5)$ & 1.09 & $0.91-1.30$ \\
\hline & Matching basic values & $3.83(1 / 5)$ & 1.06 & $0.85-1.32$ \\
\hline \multirow[t]{7}{*}{ Structure } & Effective cooperation between departments & $2.61(1 / 4)$ & 0.73 & $0.59-0.92$ \\
\hline & Organisational structure & $2.99(1 / 4)$ & 0.92 & $0.70-1.22$ \\
\hline & Change of manager, group or tasks & $1.55(1 / 4)$ & 1.19 & $0.88-1.42$ \\
\hline & Expansion & $2.74(1 / 4)$ & 1.04 & $0.92-1.17$ \\
\hline & Downsizing and transferral & $1.78(1 / 4)$ & 1.02 & $0.86-1.20$ \\
\hline & Demoted & $4.2 \%$ & 1.49 & $0.84-2.66$ \\
\hline & Promoted & $16.9 \%$ & 0.77 & $0.53-1.11$ \\
\hline \multirow[t]{2}{*}{ Management } & Relations with immediate manager & $2.78(1 / 4)$ & 0.56 & $0.42-0.75$ \\
\hline & Confidence in the management & $2.61(1 / 4)$ & 0.58 & $0.46-0.73$ \\
\hline \multirow[t]{4}{*}{ Freedom } & Freedom of decision-making & $3.13(1 / 4)$ & 0.84 & $0.64-1.11$ \\
\hline & Influence & $2.26(1 / 4)$ & 1.82 & $1.46-2.27$ \\
\hline & Freedom in working hours & $67.1 \%$ & 0.88 & $0.65-1.19$ \\
\hline & Freedom in time off & $3.71(1 / 5)$ & 0.88 & $0.76-1.02$ \\
\hline \multirow[t]{3}{*}{ Democracy } & Manifest freedom of expression & $3.05(1 / 4)$ & 1.51 & $1.25-1.81$ \\
\hline & Workplace democracy & $1.85(1 / 3)$ & 1.38 & $0.94-2.03$ \\
\hline & Procedural justice/Fairness of decision & $3.41(1 / 5)$ & 0.75 & $0.61-0.92$ \\
\hline \multirow[t]{3}{*}{ Humanity and social support } & Social support & $3.20(1 / 4)$ & 0.41 & $0.29-0.59$ \\
\hline & Humanity & $3.14(1 / 4)$ & 1.08 & $0.81-1.43$ \\
\hline & Attitude of expendability & $2.43(1 / 4)$ & 1.14 & $0.96-1.34$ \\
\hline
\end{tabular}

${ }^{1}$ Adjusted for age, sex, education, and supervisory duties.

$(\mathrm{n}=2,086)$. Among the workplace characteristics, lacks relating to level of influence and manifest freedom of expression, procedural justice, social support, confidence in the management, a good relation with the immediate manager and effective cooperation between departments were significantly related to ongoing conflicts. Further adjustment for principal employer did not influence the estimates much, nor did the estimates change much even after adjusting for work characteristics (data not shown).

This study has also inquired into the relations between sources of workplace conflict and risk and inhibiting factors (Table 2). The results are not shown here in their entirety, but the significant correlations ( $\mathrm{R}$ 0.15-0.20) have been included in the matrix below.

\section{Relationship with self-rated poor health}

Table 5 shows odds ratios and $95 \%$ confidence intervals estimating the relationship between conflicts and poor general health. There was a significant relation between conflicts in general and poor general health $(n=2,903)$, after adjusting for age, sex, marital status, 
Table 5. Associations between conflicts and poor general health $(\mathrm{n}=2,903)$. Multiple logistic regression. Standardized odds ratios

\begin{tabular}{lccccc}
\hline Conflicts & Cases $(\%)$ & $\mathrm{OR}^{1}$ & $95 \% \mathrm{CI}^{1}$ & $\mathrm{OR}^{2}$ & $95 \% \mathrm{CI}^{2}$ \\
\hline Any & $290(25.9)$ & $\mathbf{1 . 6 1}$ & $\mathbf{1 . 3 2}-\mathbf{1 . 9 7}$ & $\mathbf{1 . 2 8}$ & $\mathbf{1 . 0 3 - 1 . 5 9}$ \\
Terminated & $148(22.0)$ & $\mathbf{1 . 3 4}$ & $\mathbf{1 . 0 5}-\mathbf{1 . 7 0}$ & 1.17 & $0.91-1.50$ \\
Ongoing & $137(31.3)$ & $\mathbf{2 . 0 9}$ & $\mathbf{1 . 6 0 - 2 . 7 4}$ & $\mathbf{1 . 4 5}$ & $\mathbf{1 . 0 8 - 1 . 9 5}$ \\
\hline
\end{tabular}

${ }^{1}$ Adjusted for age, sex, marital status, birth country, education, financial situation, relationships with friends, and supervisory duties.

${ }^{2}$ Adjusted for age, sex, marital status, birth country, education, financial situation, relationships with friends, supervisory duties, as well as workplace and work characteristics (conflicting demands, emotional demands, resources, risk of transfer or dismissal, poor promotion prospects, effective cooperation between departments, relations with immediate manager, confidence in the management, influence, manifest freedom of expression, procedural justice, social support).

birth country, education, financial situation, relationships with friends, and supervisory duties. This relation remained significant even after adjustment for workand workplace characteristics. When the conflicts were categorised into two groups (ongoing/terminated), the analysis showed that the relation was mainly attributable to ongoing conflicts $(n=2,895)$. The odds ratio for ongoing conflicts remained 1.45 (CI 1.08-1.95) after adjustment for work- and workplace characteristics as well. We also adjusted for lifestyle factors and general life satisfaction which only changed the estimates marginally. In an additional analysis including 2,022 individuals, those with terminated conflicts with poor result had an unadjusted odds ratio of 2.50 (CI 1.66-3.76). This was reduced to 1.94 (CI 1.26-3.00) when adjusted for age, sex, marital status, birth country, education, economic stress, social contacts and supervisory duties, and to 1.40 (CI $0.88-2.22$ ) in the fully adjusted model (corresponding to model 2 in Table 5). The corresponding analysis of terminated conflicts with good result resulted in adjusted ORs of 1.17 (CI 0.89-1.53) and 1.09 (CI $0.82-1.45$ ) respectively. These data are not shown here.

\section{Discussion}

\section{Strengths and limitations of the study}

Our study has the general limitations of a crosssectional study, which means that it is impossible to conclude anything about causal directions. For instance, it is not known whether conditions that allow employees to speak up at the workplace will cause conflicts or whether the direction of the relationship is the opposite one, that conflicts make people speak up; or whether both directions exist at the same time. It may be that conflicts at the workplace "corrupt" fairness of decisions (organisational justice) but it may also be the other way around, that lack of fairness of decisions will cause conflicts. Do emotional demands cause conflicts or do conflicts generate emotional demands? Do people rate their health as poor because of conflicts they are involved in or do conflicts arise when people consider themselves to be in poor health? These questions cannot be answered in this study. In a future study based upon the same cohort a prospective design will be used.

Another limitation is the large number of variables in the study, which increases the likelihood of randomly occurring significance. This also results in a large number of missing values, since listwise deletion was employed. On the other hand, we have included factors previously not studied (see Appendix), which is a strength. A further major strength of the present study is that the results are representative for all workplaces with 20 or more employees in Sweden and that all kinds of jobs are represented.

\section{Patterns in the main results}

Since research on the importance of work and the workplace itself for the occurrence of workplace conflict is scarce and the studies that exist are difficult to compare, we chose not to discuss in detail the results of this investigation in relation to other results in the research area of conflicts. It is worth pointing out, however, that the present results are quite in line with those of at least one previous study ${ }^{10)}$. The major difference between the present investigation and previous research efforts is the large number of variables examined, with 21 "workplace" and ten "work (eight) and individual (two)" factors. As indicated above this taxonomy which has been introduced for this project by our group has a theoretical basis in previous literature (for a discussion see 30 ). Decision authority -according to the demand control model -and quantitative demands did not establish significant associations with workplace conflict. Goals and structure (apart from the variable co-operation between sections/work groups) were also two dimensions that turned out not to be of much importance. Also surprising is that working hours were not a source of conflict, 
Table 6. The Matrix

\begin{tabular}{|l|l|l|l|l|}
\hline Level & & Sources of conflict & Risk factors & Protective factors \\
\hline \multirow{2}{*}{ Workplace factors } & Group 1 & Leadership & Involvement in decision-making & Fairness of decisions \\
\cline { 2 - 5 } & Group 2 & & Manifest freedom of speech & Effective co-operation between departments \\
\cline { 2 - 5 } & Group 3 & $\begin{array}{l}\text { Leadership } \\
\text { Leadership } \\
\text { Colleagues }\end{array}$ & $\begin{array}{l}\text { Relationship with immediate manager } \\
\text { Social support }\end{array}$ \\
\hline Work factors & Group 4 & $\begin{array}{l}\text { Resources } \\
\text { Demands and pace } \\
\text { Patients }\end{array}$ & Conflicting demands & Resources \\
\hline Individual factors & Group 5 & & $\begin{array}{l}\text { Employment insecurity } \\
\text { Small career chances }\end{array}$ & \\
\hline
\end{tabular}

Blank cells in the matrix indicate that we have not measured occurrences in these areas.

possibly because conflicts regarding long working hours are more or less taken for granted. It was also expected that traditional workplace democracy would be an inhibiting factor, but this turned out not to be the case. Twelve of the factors investigated turned out to be significant in the context of workplace conflict. However, since the results are both extensive and complex we have also here chosen not to discuss these factors individually, the idea rather being to distinguish some form of structure by attempting to group the results. The question posed was whether any pattern could be discerned among factors that increased or decreased the likelihood of conflict, shown in Tables 3 and 4.

The question about "small career chances" and the questions regarding "risk of being transferred to other tasks against one's will" and "threat of being laid off or being given notice to quit" were formulated in such a way that the responses may have been less 'objective' than most other questions and hence more 'subjectively flavoured'. We labelled the factors "Employment insecurity" and "Small career chances". A new sublevel was therefore created and labelled "Individual factors".

In a next step the 12 significant variables were separated into a risk category and a protective category, and the workplace factors were divided into three strata or groups. This allowed the risk factors and the inhibiting factors to be sorted by pairs into the matrix created. Finally, the significant correlations between the 12 variables and the sources of conflicts in Table 2 were added to the matrix. Correlations in the order of $0.15-0.20$ obviously account for a very small part of the variance but we nevertheless decided to keep these results in the matrix. Our choice in this matter was guided by logic and not by the statistical strength of the correlations, since the aim of the matrix is to provide an overview of the results and a first basic framework for the generation of hypotheses for future research. Causality cannot be inferred because of the cross-sectional nature of the study.

If workplace conflicts are regarded not as occasional events but as part of a dynamic process there should be a balance between risk factors and protective factors; a balance that can be maintained during shorter or longer periods but can also easily be lost. The reason for this may be changes in the world outside the organisation. In order to survive in the long term, the organisation seen as an open system - must adapt or in some other way take a position with regard to the new conditions. The balance can also be disturbed by changes within the organisation. Reorganization and managerial training are examples of such changes. These may result in corrective movements. Our results give the picture of a dynamic situation where some of the risk factors and the protective factors are tied together like horses of a pair (see Groups 1, 3 and 4 in Table 6) and where there is also a dynamic relation between the levels.

The paired relationships in Table 6 (Groups 1, 3 and 4) may be thought of as follows: If the organisation develops its decision-making practices so that employees become more involved in the decision making, there will be more conflicts unless procedural justice at the workplace is concurrently improved (Group 1). There will be more conflicts at the workplace if employees tell their managers what they think, feel and want. Confidence in management and good relations with immediate managers may improve the process of handling conflicts; conflicts may therefore become more constructive. A positive change in the management's attitude to criticism from employees can facilitate the feeling among staff that they can express their true opinions and feelings. Improving social relationships and creating trust thus provides protection against the risk of conflicts arising because employees speak up (Group 3).

Emotional demands and conflicting demands (role ambiguity) are potential risk factors that are probably 
linked to the amount of resources the employee has access to. Adequate resources may reduce the amount of conflicts, therefore, or make it possible for the employees to handle more and harder emotional and conflicting demands (Group 4).

It is not known, from the results of the present study, whether there are specific risk factors involved when employees have to work together across borders within an organisation. What our results do indicate, however, is that good management may protect employees from conflict situations with other parts of the organisation by structuring the co-operation in a way that minimises conflicts (Group 2).

Small chances of career advancement can be a source of conflict, in particular in the situation where several persons within the organisation are trying to be promoted to the same position. The risk of being involuntarily transferred to new duties and the threat of dismissal may arise during reorganisation and downsizing. Our results indicate that this might be a risk factor for conflict. But strict principles and procedures for recruiting staff, respect for the legislation regulating employment conditions, and solid information about the actual situation of the business and what applies in the event of shortage of work could be important protective factors (Group 5).

Such an interpretation of our results would make it self-evident for all employees to work for improvement of the balance. But the prevailing state of balance can be desirable from the viewpoint of some parties, while others may view it as undesirable.

The outcome of a conflict is likely to depend partly on the actors' power resources and their chances of achieving a positive result. Relationships are often asymmetrical, so even in organisations. One part may on the whole lack any chance of changing the situation if the opposite part has all the line organisational power and can make all decisions regarding allocation of resources with the result that one part will experience itself as the loser and the other as the winner. However, both parties may also experience themselves as winners or as losers.

\section{Workplace conflict and health issues}

That conflicts arise is a fact of life, but 1) not necessarily unavoidable (there are risk factors to monitor as well as protective factors to enhance) and 2) not necessarily in themselves the causes of health problems. Health problems arise when conflict outcomes are negative for the affected employee(s).Our results show that self-rated health was estimated as worse among employees who reported that conflicts had ended in negative outcomes than among those without conflicts. The association between conflict and various measures of health has been demonstrated in several studies. After adjustment for a large number of social conditions that affected the results only marginally, the increased likelihood of self-reported poor health was in the order of $100 \%$. After further adjustments for work and workplace factors this increase in likelihood was reduced to about $50 \%$. These results suggest that other work and workplace factors may exist within the context in question and that there may be an effect from psychological factors as well, for example individual personality traits. Keeping in mind the serious consequences that workplace conflicts appear to have for employee health in cases with negative outcomes for the employee, the observed risk factors and protective factors provide a good starting point for effective intervention and prevention work.

\section{References}

1) Appelberg K (1996) Interpersonal conflicts at work: impact on health behaviour, psychiatric morbidity and work disability. People and Work Research Reports 7, Finnish Institute of Occupational Health, Helsinki.

2) Rahim MA (1985) A strategy for managing conflict in complex organizations. Hum Relat 38, 81-9.

3) Barki H, Hartwick J (2004) Conceptualizing the construct of interpersonal conflict. Int J Confl Manage 15, 216-44.

4) De Dreu C, Van de Vliert E (1997) In: Using conflict in organizations. De Dreu C, Van de Vliert E (Eds)., Sage Publication, London.

5) Brodal H, Nilsson L (1996) Konflikter — vad vill de lära oss? (Conflicts —do they teach us?). Balders Förlag, Järna (in Swedish).

6) Arbetsmiljöinspektionen Örebro (2002) Ohälsa och negativ stress $\mathrm{i}$ ett arbetsliv i förändring: ett underlag för tillsynsarbete utarbetat av en arbetsgrupp vid Yrkesinspektionen (numera Arbetsmiljöinspektionen) i Örebro (Ill-health and negative stress in working life in the process of change). Arbetsmiljöverket, Solna (in Swedish).

7) Leymann H (1992) Från mobbning till utslagning i arbetslivet (From bullying to elimination from working life). Publica, Stockholm (in Swedish).

8) Spector PE, Jex SM (1998) Development of four selfreport measures of job stressors and strain: interpersonal conflict at work scale, organizational constraints scale, quantitative workload inventory, and physical symptoms inventory. J Occup Health Psychol 13, 356-67.

9) Appelberg K, Romanov K, Honkasalo ML, Koskenvuo M (1991) Interpersonal conflicts at work and psychosocial characteristics of employees. Soc Sci Med 32, 1051-6.

10) De Raeve L, Jansen NWH, van den Brandt PA, Vasse 
RM, Kant I (2008) Risk factors for interpersonal conflicts at work. Scand J Work Environ Health 34, 96-106.

11) Hinds PJ, Mortensen M (2005) Understanding conflict in geographically distributed teams: the moderating effects of shared identity, shared context, and spontaneous communication. Organ Sci 16, 290-307.

12) Ayoko OB (2007) Communication openness conflict events and reactions to conflict in culturally diverse workgroups. Cross Cultural Management: an International Journal 14, 105-24.

13) Torpey MJ (2006) A case study of conflict in an educational workplace: managing personal and cultural differences. Teach Coll Rec 108, 2523-49.

14) Bruk-Lee V, Spector PE (2006) The social stressorscounterproductive work behaviors link: are conflicts with supervisors and coworkers the same? J Occup Health Psychol 11, 145-56.

15) Appelberg K, Romanov K, Honkasalo ML, Heikkilä K, Koskenvuo M (1996) Interpersonal conflicts as a predictor at work disability. A follow-up study among 15,348 Finnish employees. J Psychosom Res 40, $157-67$.

16) Romanov K, Appelberg K, Honkasalo ML, Koskenvuo M (1996) Recent interpersonal conflicts at work and psychiatric morbidity: a prospective study of 15,530 employees aged 24-64. J Psychosom Res 40, 169-76.

17) Bültmann U, Kant IJ, Van den Brandt PA, Kasl SV (2002) Psychosocial work characteristics as risk factors for the onset of fatigue and psychological distress: prospective results from the Maastricht cohort study. Psychol Med 32, 333-45.

18) Cox KB (2003) The effects of intrapersonal, intragroup, and intergroup conflict on team performance effectiveness and work satisfaction. Nurs Adm Q 27, $153-63$.

19) Cooper CL, Marshall J (1976) Occupational sources of stress: a review of the literature relating to coronary heart disease and mental ill health. J Occup Psychol 49, 11-28.

20) Albertsen K, Nielsen ML, Borg V (2001) The Danish psychosocial work environment and symptoms of stress: the main, mediating and moderating role of sense of coherence. Work Stress 15, 241-53.

21) Laposa JM, Alden LE, Fullerton LM (2003) Work stress and posttraumatic stress disorder in ED nurses/ personnel. J Emerg Nurs 29, 23-8.

22) De Raeve L, Jansen NWH, van den Brandt P A, Vasse R, Kant IJ (2009) Interpersonal conflicts at work as a predictor of selfreported health outcomes and occupational mobility. Occup Environ Med 66, 16-22.

23) Oxenstierna G, Widmark M, Westerlund H, Theorell $\mathrm{T}$ (2005) Den höga sjukfrånvaron - problem och lösningar (Sickness absence - problems and solutions). In: Konflikter och sjukskrivning (Conflicts and sick leave). Marklund S, Bjurvald M, Hogstedt C, Palmer E, Theorell T (Eds.), Arbetslivsinstitutet, Försäkringskassan, Institutet för Psykosocial Medicin, Statens folkhälsoinstitut, Stockholm (in Swedish).

24) Karasek R, Gardell B, Lindell J (1987) Work and nonwork correlates of illness and behaviour in male and female Swedish white collar workers. J Occup Behav 8, 187-207.

25) Fujiwara K, Tsukishima E, Tsutsumi A, Kawakami N, Kishi R (2003) Interpersonal conflict, social support, and burnout among home care workers in Japan. J Occup Health 45, 313-20.

26) Magnusson Hanson LL, Theorell $T$, Beck $P$, Rugulies R, Burr H, Hyde M, Oxenstierna G, Westerlund H (2009) Psychosocial working conditions and depressive symptoms -findings from the Swedish Longitudinal Survey of Health (SLOSH). Int Arch Occup Environ Health 82, 951-60. Epub 2009 Feb 24.

27) Hagerty BM, Williams RA (1999) The effects of sense of belonging, social support, conflict, and loneliness on depression. Nurs Res 48, 215-9.

28) Kinsten A, Magnusson Hanson L, Hyde M, Oxenstierna G, Westerlund H, Theorell T (2007) SLOSH - Swedish longitudinal survey of health: a national representative psychosocial survey of the Swedish working population. Stress Research Reports No 321, Stress Research Institute, Stockholm.

29) Magnusson Hanson LL, Theorell T, Oxenstierna G, Hyde M, Westerlund H (2008) Demand, control and social climate as predictors of emotional exhaustion symptoms in working Swedish men and women. Scand J Publ Health 36, 737-43.

30) Oxenstierna G, Widmark M, Finnholm K, Elofsson S (2008) A new questionnaire and model for research into the impact of work and the work environment on employee health. Scand J Work Environ Health (Suppl 6), 150-62.

31) Bjorner Bue J (1996) Self-rated health: a useful concept in research, prevention and clinical medicine. Swedish Council for Planning and Coordination of Research [Forskningsrådsnämnden (FRN)], Report 96, 9. 